\title{
Research on the Modern Chinese Values to Restore Mode from the Perspective of Traditional Culture
}

\author{
Yu Mi \\ Sichuan Vocational and Technical College, SuiNing 629000, China.
}

\begin{abstract}
This paper presents the novel research on the modern Chinese values to restore mode from the perspective of traditional culture. Socialist core values is the core member of the socialist value system, guidance on other social values, and from the deepest level science reflects the values of the essential attribute of socialism. It is the characteristics of socialism with Chinese characteristics in the embodiment of the value level are the core component of the socialist core value system. Under this basis, we propose the corresponding theories on the topics that are innovative.
\end{abstract}

Keywords: Modern; restore mode; values; traditional culture; perspective; innovation.

\section{Introduction}

Advocate and practice the socialist core values are the backbone of the contemporary Chinese ideological and cultural life. Guided by the Marxist socialist core value is a Marxist scientific nature, value the personal and national value choice and value pursuit, which is highly concise, and focused. But the formation and accumulation of the socialist core values in China, cannot leave the history of Chinese tradition and culture, extensive and profound and the historic Chinese excellent traditional culture provides the socialism core values concise and cultivating the rich cultural resources.

Culture is created by human in the process of social and historical development of the sum total of material wealth and spiritual wealth. Has the advanced and backward culture. Advanced culture is to adapt to the requirement of development of that productive forces, represent the future development direction, in many ideological trend of general increasingly shows its scientific culture. The different historical period, the connotation of advanced culture is different permeated by science, especially in today's world, only the scientific spirit of the culture that can be classified as advanced culture.

This transformation has on the economy and will further the cause of social political, cultural and other aspects of the profound changes. Our country is in the conversion from the first stage to the second phase of social transformation. The change of the social transformation will inevitably cause the values that could be reflected from the listed aspects. (1) The interests of the value object of basic consciousness. In natural economic society, individuals related by blood or by regional natural ties attached to the group, and correspond to the natural bond is the patriarchal concept and filial piety as the core of the ethics. Under the planned economy system, that there is no fundamental change. (2) The diversity of the value subject consciousness. In natural economic society, the values of the subject consciousness are a universal consciousness. Under the planned economy system, that there is no fundamental change. (3) The diversity of values and conflict. Value target of the change of the subject consciousness and value pursuit, will generate multiple values. The newly formed multiple values and has been old, but still exist values intertwined make the values of pluralism presents for situation [1].

Huge grand Chinese traditional culture, but its inherent basic characteristics, namely historical shows differs from other ethnic culture of basic unique cultural features or temperament is clear. And through the complicated cultural phenomenon, reveal the characteristics and temperament, in basic traditional Chinese culture from philosophy level for us to get to a clear understanding of Chinese traditional culture and the overall grasp, no doubt is of great help. From the angle of social ideology, talk about cultural characteristics is already include the level of ideology and culture, but if the clues of ideological culture schools which alone will no doubt more see clear, is conducive to more depth to set the multidimensional characteristics of traditional culture. Below we will in accordance with the economic form, social form, social ideology and cultural clues of schools of simply analyze the basic characteristics of the Chinese traditional culture. The traditional culture of a country on its plays the 
fundamental role in the development of modern economy while another view is that no positive and negative culture itself, the key lies in how to use it. In later sections, we will discuss our perspective of the issues in detail and the figure one shows the principles of the modern Chinese values [2].

\section{Chinese Values}

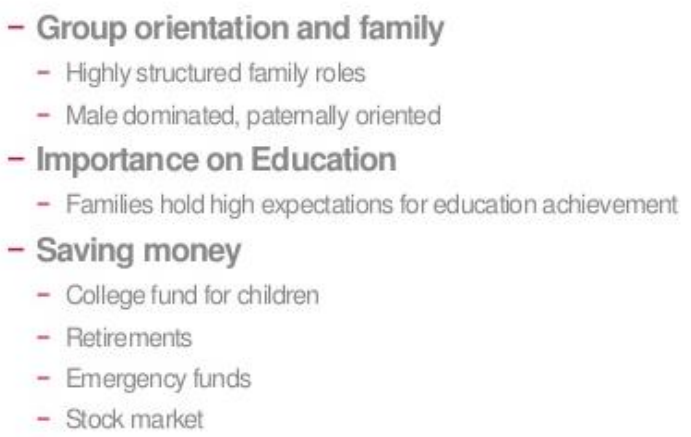

There is a fine line between stereotypes and actual Chinese values.

Fig. 1 The Principles of the Modern Chinese Values

\section{Our Proposed Methodology}

\subsection{The Properties of the Values.}

Values is the study of socialism is an important perspective. But for a long time, in the study of theory of scientific socialism, the scientific nature of Marxism is a high degree of attention, and value is neglected or has intention to not intentional of avoidance. This caused a serious lack of theory both at the same time also lead to serious mistakes in practice. In fact, the intrinsic values in the theory, movement and the system of general socialism, in a sense, whether socialism theory, movement, or the socialist system, is the pursuit of socialist value and its implementation.

Socialist core values only penetrates into every aspect of daily life, only with the specific, can sense the day-to-day work of the form, can make people perceive it, understand it in their life. As a result, all types of schools at all levels actively conducive to carry forward the general mainstream values of life situation and cultural atmosphere, in the socialist core values of the basic day-to-day work, specific, visualization, and life. Specifically, the day-to-day education as a kind of comfortable, continuous and regular education activities, can put the socialist core values education from a limited class extends to the vast reality life and make everyday life not only students experience, cognitive, recognition and practice the socialist core values [3-4].

System of thought or ideology is a process of the social life system, theoretical reflection that is the understanding of the world. It can make us insights into the human activities, and belong to the world their own basic structure, at the same time can make us understand these activities and the world as organic whole. All human beings "life event" is directed to create value, through their own activities make the world to meet the need of human beings, the world become true unity of the world, the implementation of that significant value in the development of the world. Therefore, philosophy or ideology to reflect social life process, is not only a reflection of an intuitive, descriptive, and contain the value of creative consciousness. Socialism is to adapt to the proletariat and advances human get rid of the exploitation and oppression of capital, the needs of the liberation of mankind was proposed and established. So for the proletariat and the progress of human society, no matter from the theory, sport is a kind of system, means a kind of with the survival and development of the proletariat and the masses of the people that is closely related with the liberation of their fundamental value.

\subsection{The Modern Chinese Values.}

The complex of the world, but is that it consists of endless things with endless movement, rather than a single element with a single movement, therefore, the idea of a single and single perspective, is not enough to reflect the face of the world. China in the past because of thousands of years of feudal autocratic that rule is a unified centralized system, correspondingly, unified values or unified values dominate, and form a kind of deep, has a long history of traditional thoughts. 
The Chinese nation has a long history and profound traditional culture that embodies the Chinese nation's deep value pursuit, for the tenacity of the Chinese nation and development provides a rich nourishing. Socialist core values is the founding of the contemporary China, is a spiritual support, and in the development of the Chinese national rejuvenation of the China's people's daily unknowingly spiritual sustenance, we must be rooted in splendid culture of tradition and deep soil of a nation.

Cultural values thought, looking at the world frontier scientific and cultural development as is the socialist cultural values in order to adapt to a variety of social conditions and the expansion of its own logic, for the cultural values of the socialism with Chinese characteristics to further improve opened up new horizons. In ideological and the moral qualities and scientific cultural quality education as the main content of socialist spiritual civilization is superior to the basic point of capitalism as is human's free comprehensive development. From the point of view of the general human society development, pioneered by the bourgeoisie civilization than before all civilization is a historical progress [5].

Basically, every age people's values are from their life of society as is a certain social material life style, political law system, the concept of cultural factors such as traditional beneficence, subtly, the result of the influence and shape. So, values must timely, nationality and class nature.

\begin{tabular}{|c|c|c|}
\hline Directness & Indirect & Explicit \\
\hline Enthusiasm & Reserved $\vdash$ & Expressive \\
\hline Assertiveness & Subtle & Firm \\
\hline Self-Promotion & -1 & "We" \\
\hline Formality & Formal & Casual \\
\hline Personal Disclosure & Private & Open \\
\hline
\end{tabular}

\subsection{Traditional Culture Characteristics.}

Fig. 2 The Characteristics of the Modern Chinese Values

The Chinese traditional culture is refers to the history of Chinese nation formed with Confucianism as the core, with a variety of ideological content of the social culture system. Its main contents and thoughts in ancient attribute is basic finalize the design, and presents the independence, stability and openness, creativity, the character of the both. As the degree of globalization, countries in the field of ideology and culture exchange and collision also showed a trend of increasing.

Agricultural characteristics of Chinese culture is appropriate, it shows that the natural economy based on the agricultural production is the dominant aspects of the material basis of basic Chinese traditional culture and dominant strength, at the same time, the agricultural economy and is not the only or all of the economic basis, the traditional culture with other economic industry and interweave each other and form a kind of multiple economic structure, as it is this agricultural natural economy as the core of multiple economic structure to shape the history of Chinese traditional culture provides the influence of the economic power of basic action. From the national consciousness, strengthen law and general phenomena of contemporary China and the ethnic problems, the formation of the nation are also is closely related to certain political interests, but these phenomena are the appearance of issues.

Thus it can be seen that once the same emphasis on distinguishing cultural sexual function, culture has become the purpose of the political tool, also had the characteristics of political ethnic traditional culture. At the same time, the distinguishing characteristics of culture as often will also become a kind of meet curious "he" culture of business selling point. An overall national traditional culture activity, political and commercial performance was born. We analyze that the relationship between ethnic and cultural front, recognize that culture is only a means of national existence and development. Although the culture of human development has a strong binding, but it is not a human being or the individual inherent in the inevitable choice, it has dual attributes. But as a whole culture, it can be divided into the material culture, system culture and spiritual culture three levels, and the 
first two levels, mainly producing and maintaining, and spiritual culture to a certain extent that is identified.

\subsection{Modern Culture Integration.}

Since the human into the knowledge economy and information age, increasing globalization of the world economy has entered a new historical stage of the development. This stage with the traditional economic development of the fundamental difference lies in: determine the leading factor in the economic and social development has been from previous technology, capital and other production information into knowledge, information and culture with modern character. That is to say, culture in the process of the development of productive forces began to play an increasingly important role.

In front of the culture and "modern" two words becomes a relative concept rather than an absolute concept. Thus, the concept of "modern culture" is a dynamic rather than a static concept, is a relative concept of traditional culture. History in the extension, the modern in the passage today's modern is the ancient tomorrow dominated by the philosophy of "ancient culture, modern culture dominated by science and the ancient only national culture and regional culture, formed the international modern culture, it is a science and technology as the core, the eclectic the essence of different cultures and the countries of the world's elite to create new culture. The relationship between culture and the realistic society, the role of culture as culture, he argues, has guidance and control action to the society, it is not only to guide and control people's mental, emotional, and provide people with values, ideas, methods, norms, so that people in a certain cultural system oriented to life, action, and also then influence the development of modern social economy and culture.

\section{Summary}

In this paper, we conduct research on modern Chinese values to restore mode from the perspective of traditional culture. The values of country or nation are the spiritual home of the people, the country or nation is the soul of this country or the national culture and spirit. Value is a system, and therefore can be said to be the concept of value system. When the value of this kind of idea system reality into reality value system, it constitutes the culture of a country or nation's deep structure. In the structure of the concept of value system, has its core structure, this is what we now call the core value system and core values. We analyze the corresponding issues in detail that is meaningful.

\section{References}

[1]. Quek, Karen Mui-Teng, and Cheryl L. Storm. "Chinese values in supervisory discourse: Implications for culturally sensitive practices." Contemporary Family Therapy 34.1 (2012): 44-56.

[2]. Luke, Allan. East meets West in teacher preparation: Crossing Chinese and American borders. Ed. Wen Ma. Teachers College Press, 2014.

[3]. Lee, Jae-IL, et al. "Reference values of hematology, chemistry, electrolytes, blood gas, coagulation time, and urinalysis in the Chinese rhesus macaques (Macaca mulatta)." Xenotransplantation 19.4 (2012): 244-248.

[4]. You, Shaohua, et al. "Normal values of nasal NO and exhaled NO in young Chinese people aged 9-22 years." World Journal of Otorhinolaryngology-Head and Neck Surgery (2016).

[5]. Jayaratne, Yasas SN, Curtis K. Deutsch, and Roger A. Zwahlen. "Nasal Morphology of the Chinese Three-Dimensional Reference Values for Rhinoplasty." Otolaryngology--Head and Neck Surgery 150.6 (2014): 956-961. 